\title{
Hereditary distal spinal muscular atrophy with vocal cord paralysis
}

\author{
I D YOUNG AND P S HARPER
}

From the Section of Medical Genetics, Department of Medicine, University Hospital of Wales, Cardiff

SUMMARY A large kindred is described in which an unusual form of spinal muscular atrophy is segregating in an autosomal dominant manner. The disease presents most commonly in the teens with small muscle wasting in the hands, particularly involving median nerve musculature. Subsequently distal muscle wasting and weakness occur in the lower limbs. Vocal cord paralysis is a characteristic and potentially hazardous feature. No previous report of this condition has been found.

The spinal muscular atrophies comprise a large group of hereditary disorders characterised by degeneration of the anterior horn cells in the spinal cord and to a lesser extent in the motor nuclei of the brain stem, resulting in progressive muscle weakness and wasting. The diversity of clinical findings in these disorders makes classification difficult.

This report describes a large family in which an unusual form of chronic distal spinal muscular atrophy is segregating; the upper limb changes precede those in the lower limbs, and are accompanied by laryngeal involvement.

\section{Case histories}

The family pedigree is shown in fig 1 . Subject III 24, the father of the proposita, has been intensively investigated and his findings are described in detail below. Relevant clinical data on other affected family members are included and summarised in table 1 . Table 2 shows the results of nerve conduction studies.

III 24 . Born in 1929, this man initially complained of bilateral wasting of thenar eminence musculature at the age of 14 years, associated with stiffness and curling of his fingers. When aged 20 years he noticed distal weakness and wasting in the lower limbs. By this time his voice had become husky and he could neither sing nor shout. By age 30 years walking became painful and difficult. Insidious progression of distal wasting and weakness has severely limited

Address for reprint requests: Dr PS Harper, Section of Medical Genetics, University Hospital of Wales, Heath Park, Cardiff CF4 4XW Wales.

Accepted 22 January 1980 his activity so that he can no longer earn his living. At present he can walk only for short distances, drives with difficulty and can barely hold a pen.

His general health has been good. He underwent appendicectomy aged 25 years without incident. However, since age 40 years he has noticed increasing dyspnoea on effort, which has contributed to impaired exercise tolerance. He has no other pulmonary symptoms and has never smoked.

At recent examination he showed marked distal wasting and weakness with typical "inverted champagne bottle" legs and bilateral pes cavus (fig 2). Severe wasting of small hand musculature, particularly the thenar eminences, was noted (figs 3 and 4). Despite full passive movements he was unable to extend the medial three digits in both hands. Deep tendon reflexes were absent at wrists and ankles. No thickened nerves were palpated nor myotonia elicited. His outstretched hands showed a pronounced tremor. Sensation was intact.

Table 1 Summary of affected family members

\begin{tabular}{|c|c|c|c|c|c|c|}
\hline & Sex & $\begin{array}{l}\text { Age } \\
(y r)\end{array}$ & $\begin{array}{l}\text { Age at } \\
\text { onset } \\
\text { (yr) }\end{array}$ & $\begin{array}{l}\text { Vocal cord } \\
\text { changes }\end{array}$ & $\begin{array}{l}\text { Upper limb } \\
\text { involvement }\end{array}$ & $\begin{array}{l}\text { Lower limb } \\
\text { involvement }\end{array}$ \\
\hline III 24 & $\mathbf{M}$ & 50 & 14 & Left cord fixed & $+t+$ & +++ \\
\hline IV 25 & $\mathbf{F}$ & 23 & 16 & Hoarse voice & ++ & + \\
\hline III 15 & $\mathbf{M}$ & 57 & 14 & Right cord fixed & +++ & ++ \\
\hline IV 23 & $\mathbf{F}$ & 25 & 12 & Left cord fixed & ++ & + \\
\hline III 17 & $\mathbf{F}$ & 57 & 11 & Bilateral palsy & ++ & +++ \\
\hline IV 24 & $\mathbf{M}$ & 33 & 13 & Bilateral palsy & ++ & ++ \\
\hline III 5 & $\mathbf{F}$ & 56 & 15 & Left cord fixed & ++ & - \\
\hline IV 10 & $\mathbf{F}$ & 35 & 15 & - & + & - \\
\hline III 25 & $\mathbf{F}$ & 42 & 31 & Hoarse voice & +++ & + \\
\hline
\end{tabular}


Table 2 Electrophysiological studies

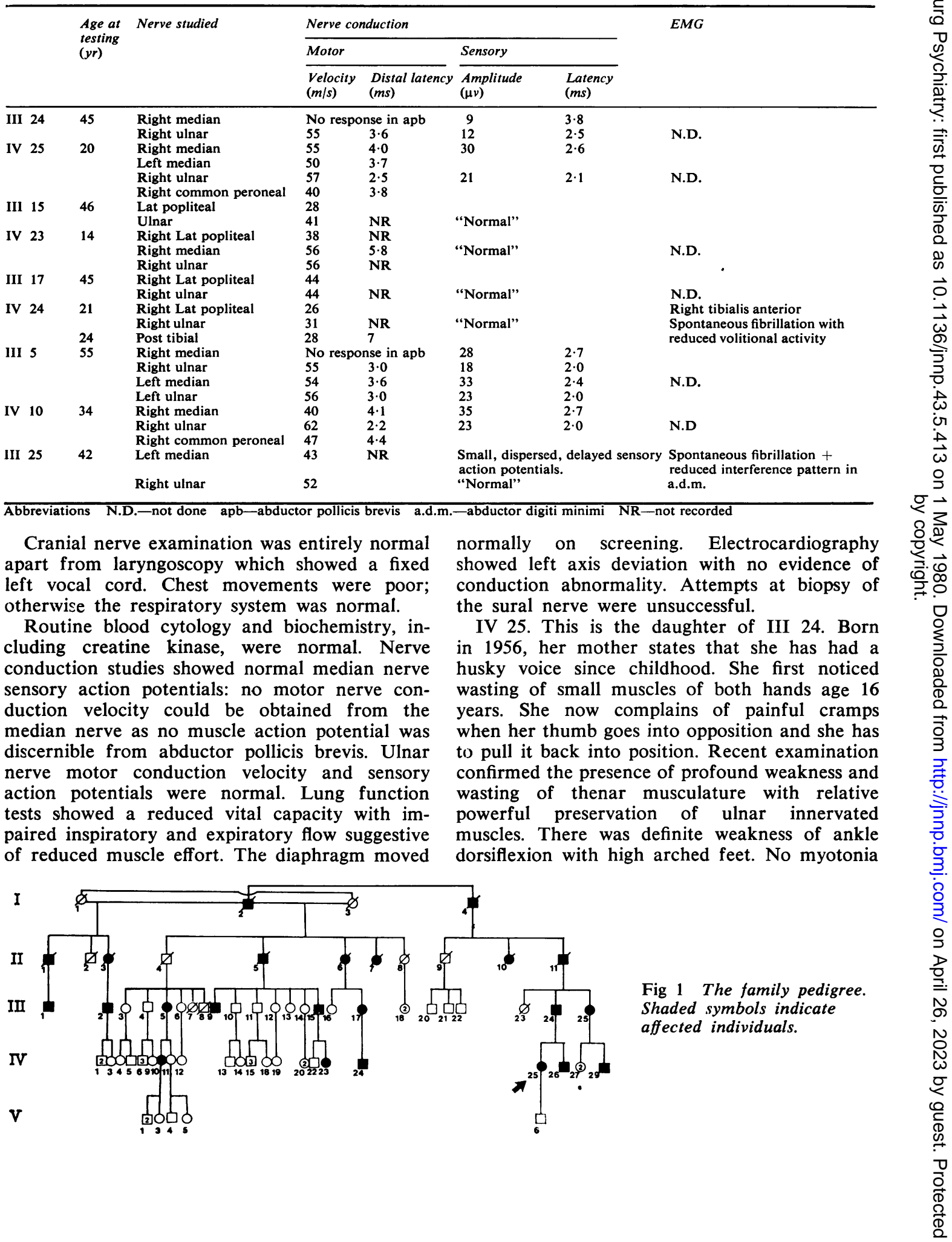




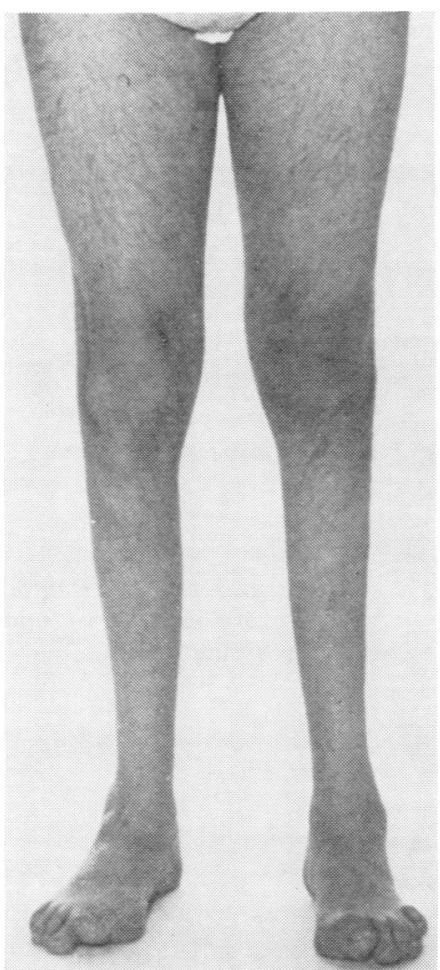

Fig 2 Shows distal wasting in lower limbs giving inverted "champagne bottle" appearance.

was elicited. All reflexes were present and sensation intact. Electrical studies showed normal sensory nerve action potentials, with normal motor nerve conduction velocities.

Her 21 year old brother, IV 26, has recently noted weakness in both thumbs along with a husky voice.

III 15. This 57 year old man dates the onset of his illness to age 14 years when he noticed weakness in his hands, followed shortly afterwards by lower limb weakness. Recent examination showed gross distal atrophy in upper and lower limbs, most marked in the hands. Laryngoscopy showed tilting of the right arytenoid with immobility of the right vocal cord.

IV 23. The 25 year old daughter of III 15 first noticed weakness in both thumbs when aged 12 years, when her voice also became hoarse. At examination, she had wasting and weakness of both thenar eminences and the first dorsal interossei. Laryngoscopy showed tilting of the left arytenoid with immobility of the left vocal cord.

III 17. This severely disabled 57 year old lady dates the onset of her condition to age 11 years, when she began to walk on her toes. This is the only member of the family where lower limb involvement preceded that in the upper limbs, which appeared ten years later. By age 37 years she was noted to have bilateral abductor cord palsies compromising her airway and contributing to recurrent chest infections. These problems were very successfully relieved by a left Woodman's operation.

IV 24. The 33 year old son of the above lady first noticed a weak grip when age 13 years with rapid progression to marked distal weakness and atrophy. Dyspnoea on effort was noted. Laryngoscopy revealed a fixed left vocal cord with limited abduction of the right, resulting in an aperture of $7 \mathrm{~mm}$. Electromyography revealed moderately severe partial denervation in tibialis anterior and the plantar flexors of the right foot.

III 5. This 56 year old lady first noticed muscle wasting in her right thumb when aged 19 years, followed by onset of a husky voice 10 years later. She has no lower limb involvement. Her left vocal cord is immobile.

IV 10. The 35 year old daughter of the above lady has a 20 year history of wasting of both thenar eminences. Clinically her voice and lower limbs are normal.

II 4. The father of III 5 is said by all his living relatives, to have been unaffected. His voice was strong and he worked as a miner until his death from peritonitis aged 37 years, caused by untreated appendicitis due to his reluctance to consult a doctor. No photographs or medical records of this man are available.

III 25. This 42 year old lady first complained of paraesthesiae in median nerve distribution 11 years ago, when examination showed weakness and wasting of the small muscles of the right hand, with minor wasting of the left hand. Bilateral pes cavus was also noted. Recent examination showed an almost useless right hand with a grossly wasted and paralysed thenar eminence. Milder but similar changes were present in the left arm. This lady was unusual in that she showed sensory loss in a glove distribution up both forearms, although both history and examination were complicated by a large functional overlay. She has also complained of a husky voice and weak cough. Her 18 year old son, IV 29, has started to complain of wasting and weakness in both hands.

\section{Discussion}

NEUROLOGICAL ASPECTS

These patients all share the common feature of 


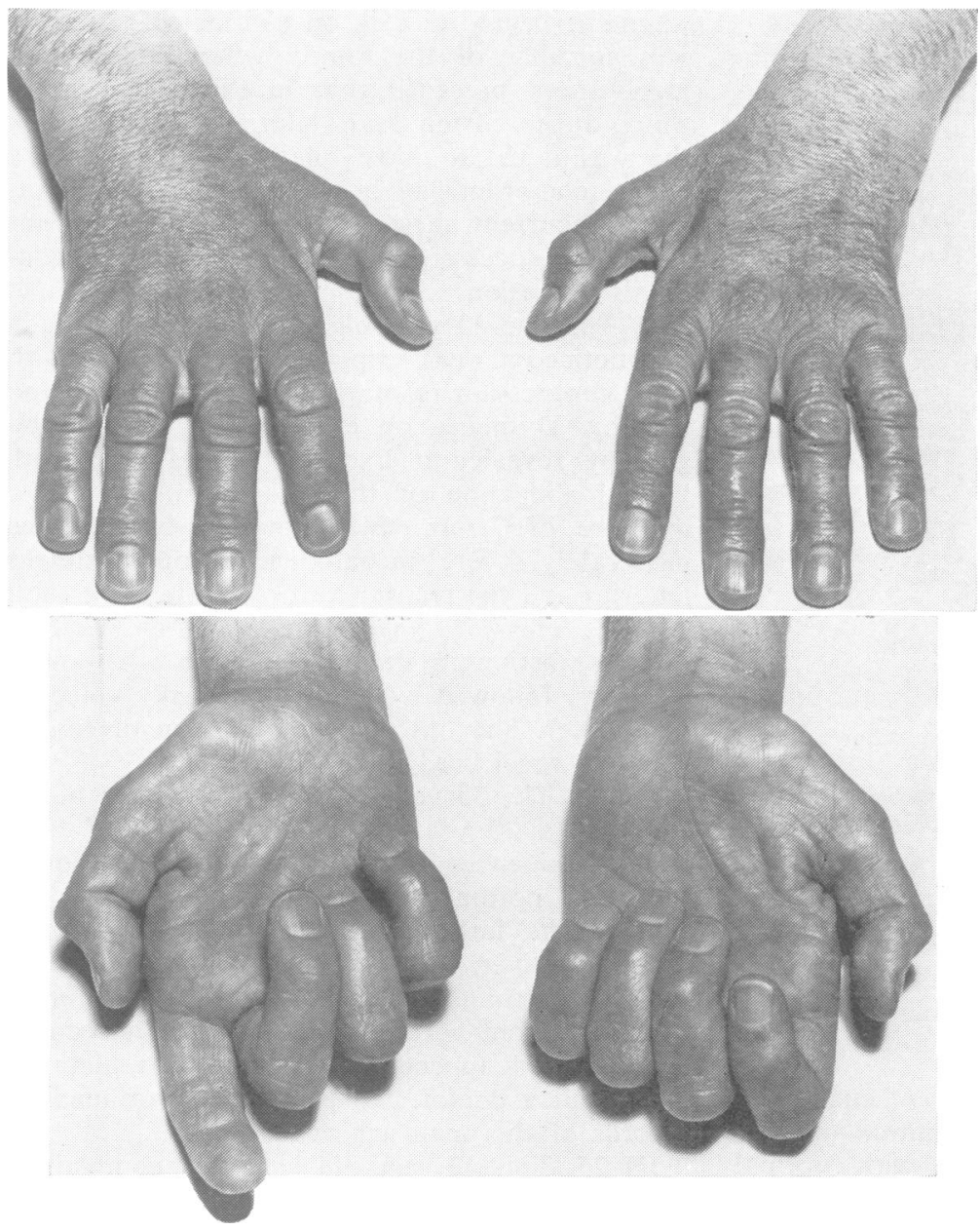

Figs 3 and 4 Demonstrate severe wasting of small hand musculature.

insidious onset of progressive distal muscle wasting and weakness, usually appearing during the teenage years with upper limb changes preceding those in the lower limbs. In all patients the onset has been gradual and the course prolonged.

The main differential diagnosis rests between a distal spinal muscular atrophy and CharcotMarie-Tooth disease. Dyck and Lambert ${ }^{12}$ have shown that Charcot-Marie-Tooth disease may include at least three pathological disorders. The first of these is a "hypertrophic" neuropathy showing segmental demyelination in the peripheral nerve with marked reduction in nerve conduction. In the second "neuronal" type, axonal degeneration is found in association with normal nerve conduction. This subdivision into two main types has been confirmed on the basis of nerve conduction ${ }^{3}$ and sural nerve biopsy studies. ${ }^{4}$ The third group consists of a rare progressive "spinal" form of the disease presenting with profound distal weakness and atrophy in the lower limbs with no sensory abnormality. In the four patients described the onset was insidious and the course prolonged with nerve conduction velocities in the normal or low normal range. In this group the primary disease process is believed to consist of degeneration of the anterior horn cell and so this form could equally well be classified as a distal spinal muscular atrophy.

In the present family the absence of sensory changes in combination with the electrophysiological findings of normal (or low normal) motor and sensory conduction with chronic partial denervation are most consistent with a diagnosis of chronic distal spinal muscular atrophy. In some affected members with severe longstanding 
disease the slight reduction in motor nerve conduction velocity may be attributed to loss of large motor neurones. The absence of pyramidal signs and the slowly progressive course of the disease, make it unlikely that the condition in this family is motor-neurone disease.

Only one patient showed sensory changes. In this lady the presence of a large degree of functional overlay and the normal ulnar sensory action potentials indicate that the sensory loss of glove distribution in the upper limbs may have been a spurious observation. The clinical features in this lady are consistent with an associated carpal tunnel syndrome.

There have been several reports of distal spinal muscular atrophy occurring in more than one member of a family. Meadows and Marsden ${ }^{5}$ described three elderly siblings who had suffered from weakness of the hands from childhood with later onset of mild changes in the lower limbs occurring in two of these patients. Pedigree interpretation in this family is complicated by the fact that their father suffered from a similar but clearly different neurological disorder with marked pyramidal signs, but inheritance of the disease affecting the siblings was probably autosomal recessive. In a subsequent publication ${ }^{6}$ this sibship is again described along with three other unrelated patients showing distal symmetrical chronic spinal muscular atrophy. None of these patients showed laryngeal involvement.

Autosomal dominant transmission of distal spinal muscular atrophy has also been described, involving two generations in one family, ${ }^{7}$ and three generations in two further families. ${ }^{78}$ The initial complaint was of lower limb involvement. Six unrelated patients with a form of distal chronic spinal muscular atrophy affecting the hands have recently been described. ${ }^{9}$ None of these patients had any relevant family history.

In none of these cases also was there evidence of any laryngeal involvement.

In the subjects of our report only one affected member (IV 10) had a normal voice at the time of examination. All others showed at least unilateral abductor paralysis causing an immobilised fixed cord. In those with bilateral involvement (III 17 and IV 24), the airway had been severely compromised. Individual families have been reported showing adductor or abductor laryngeal paralysis. Plott ${ }^{10}$ described three brothers with congenital laryngeal abductor paralysis. These boys were also mentally retarded. A family has been described where three male infants had laryngeal stridor due to abductor paralysis, with severe mental and physical retardation. ${ }^{11}$ The authors proposed that an abiotrophy of the middle part of the nucleus ambiguus was the most likely pathology. Autosomal dominantly inherited adductor laryngeal paralysis has been reported with a possible linkage to HLA loci on chromosome $6 .{ }^{12}$ No other clinical abnormalities were present in affected individuals.

\section{GENETIC ASPECTS}

Genetic heterogeneity in spinal muscular atrophy is well recognised and most forms of conventional Mendelian inheritance have been described. ${ }^{13}$ Allelomorphic activator genes have also been postulated. ${ }^{14}$ The pedigree of our family is entirely consistent with autosomal dominant inheritance with several examples of male to male transmission. There is no evidence that the sex of the individual alters disease severity. It is notable that the disease pattern tends to be very similar in affected parent and child.

Variable expressivity and complete lack of penetrance of the mutant gene are well recognised features of autosomal dominant conditions. In this family one individual (IV 10) showed only bilateral thenar wasting at age 35 years, whereas her second cousin (IV 24) was seriously incapacitated at age 33 years.

It is possible that II 4 represented true lack of penetrance. In favour of this is his alleged normality and the teenage onset in most other family members. However, his reluctance to seek medical advice when he had appendicitis may have been based on a realisation of impending muscle weakness with all the implications that would hold for a miner in a depressed area in 1930.

An alternative explanation for the findings in this family is that two discrete disorders might be segregating, the one being a spinal muscular atrophy and the other a laryngeal palsy. Mathematically this is extremely unlikely unless the loci are so closely linked that recombination does not occur. It is much more probable that the clinical features of this condition represent the pleiotropic effects of a single mutant gene.

\section{Conclusion}

The clinical features in this family appear to be unique and we are unaware of any other reports describing this condition. Electrophysiological data indicate that the basic pathology lies in the anterior horn cell and thus this condition may be classified as a spinal muscular atrophy. 
This report provides further evidence of the wide degree of heterogeneity present in this group of disorders.

We are indebted to all staff of the University Hospital of Wales who have assisted in this study. In particular, we thank Dr CEC Wells for referring the family and Drs JG Graham, INF McQueen and D Scruton for the nerve conduction studies. Our thanks also go to Mr RB Bradshaw, Cardiff, Dr C Crawford of Napier, New Zealand and Dr P Hudgson, Newcastle for providing details of family members under their care, and to Professor PK Thomas for advice on the preparation of the manuscript.

This paper was presented at the Clinical Genetic Society in Oxford, April 1979.

\section{References}

1 Dyck PJ, Lambert EH. Lower motor and primary sensory neuron diseases with peroneal muscular atrophy. Part 1. (Neurologic, genetic and electrophysiological findings in hereditary polyneuropathies). Arch Neurol 1968; 18:603-18.

2 Dyck PJ, Lambert EH. Lower motor and primary sensory neuron diseases with peroneal muscular atrophy. Part 2. (Neurologic, genetic and electrophysiological findings in various neuronal degenerations). Arch Neurol 1968; 18:619-25.

3 Thomas PK, Calne DB. Motor nerve conduction velocity in peroneal muscular atrophy: evidence for genetic heterogeneity. J Neurol Neurosurg Psychiatry 1974; 37:68-75.
4 Behse F, Buchthal F. Peroneal muscular atrophy (PMA) and related disorders-II. Brain 1977; 100:67-85.

5 Meadows JC, Marsden CD. A distal form of chronic spinal muscular atrophy. Neurology (Minneap) 1969; 19:53-8.

6 Meadows JC, Marsden CD, Harriman DGF. Chronic spinal muscular atrophy in adults. Part 2. Other forms. J Neurol Sci 1969; 9:551-66.

7 McLeod JG, Prineas JW. Distal type of chronic spinal muscular atrophy. Clinical, electrophysiological and pathological studies. Brain 1971; 94: 703-14.

8 Nelson JW, Amick LD. Heredofamilial progressive spinal muscular atrophy: a clinical and electromyographic study of a kinship Neurology (Minneap) 1966; 16:306.

9 O'Sullivan DJ, McLeod JG. Distal chronic spinal muscular atrophy involving the hands. J Neurol Neurosurg Psychiatry 1978; 41:653-8.

10 Plott D. Congenital laryngeal-abductor paralysis due to nucleus ambiguus dysgenesis in three brothers. $N$ Engl J Med 1964; 271:593-7.

11 Watters GV, Fitch N. Familial laryngeal abductor paralysis and psychomotor retardation. Clin Genet 1973; 4:429-33.

12 Mace M, Williamson E, Worgan D. Autosomal dominantly inherited adductor laryngeal paralysis -a new syndrome with a suggestion of linkage to HLA. Clin Genet 1978; 14:265-70.

13 Emery AEH. The nosology of the spinal muscular atrophies. J Med Genet 1971; 8:481-95.

14 Zellweger H, Hanhart E, Schneider HJ. A new genetic variant of the spinal muscular atrophies in infancy. J Med Genet 1972; 9:401-7. 